\title{
Searching for Phytoferritin in Unstained Plant Sections
}

\author{
M. Gajdardziska-Josifovska* and H. A. Owen** \\ *Department of Physics, ** Department of Biological Sciences, University of Wisconsin \\ Milwaukee, P. O. Box 413, Milwaukee, WI 53201
}

Iron is one of the most important transition metals for life on Earth. It is essential for both respiration and photosynthesis. Healthy bacterial, plant and animal cells need a well-controlled concentration of iron, storing the excess in oxidized bio-available form with the use of the iron storage protein ferritin. Our study focuses on phytoferritin and aims to determine the structure of the oxidized iron stored inside plant cells. We recently performed electron diffraction experiments to discover nanocrystalline botanical magnetite $\left(\mathrm{Fe}_{3} \mathrm{O}_{4}\right)$ [1], haematite $\left(\mathrm{Fe}_{2} \mathrm{O}_{3}\right), \varepsilon-\mathrm{Fe}_{2} \mathrm{O}_{3}$, and $3 \mathrm{CaO} \cdot \mathrm{Fe}_{2} \mathrm{O}_{3} \cdot \mathrm{H}_{2} \mathrm{O}$ [2] in biochemical extracts from grass cells. In combination with a modified centrifugation procedure, and with TEM imaging, we also found the first evidence for correlation between iron nanocrystal structure and modes of biological self-assembly [2]. To confirm that the biochemical extraction does not affect the identification of botanical iron biominerals, it is important to develop methods that will allow electron diffraction studies of phytoferritin in unstained sectioned plant cells. Here we report our first success in this direction, using an iron starvation followed by re-supply treatment that induces formation of phytoferritin in new growth.

Bean seeds (Phaseolus vulgaris L. Scarlet Runner) were soaked in water, planted in pots of sand, and placed in a $23^{\circ}$ growth chamber at 16 hours day $/ 8$ hours night. After 10 days, plants were transferred to $150 \%$ Hoagland's solution (with $63 \mathrm{mg} / \mathrm{L}$ Sequestrine $330 \mathrm{Fe}$, giving $6.3 \mathrm{mg} / \mathrm{L} \mathrm{Fe}$ concentration) for hydroponic growth. After 5 days, plants were transferred to Hoagland's solution without iron and grown until chlorotic. Sequstrine 330 was then added to the solution for a final iron concentration of $12.6 \mathrm{mg} / \mathrm{L}$. After 3 days, the most apical leaves, dark green in color, were removed from the plants and prepared for TEM by conventional methods. Biological TEM investigations, using osmicated samples and $75 \mathrm{keV}$ electrons, confirm the presence of phytoferritin agglomerates in chloroplasts (e.g. Fig. 1). The challenge is to find such agglomerates in unosmicated sections at the higher energies needed for HREM (e.g. $300 \mathrm{keV}$ in the Hitachi H9000NAR microscope employed for structure analysis). A somewhat cumbersome but working strategy is to use finder grids and lower electron energies to locate phytoferritin agglomerates and record their position with respect to the cell walls (e.g. Fig. 2 recorded in Hitachi H-600 at $75 \mathrm{keV}$ ). Broad angle dark field imaging at $300 \mathrm{keV}$ reveals the cell walls with dark contrast allowing the finding of the identified cells with phytoferritin. The bright field contrast from the phytoferritin nanoparticles is too poor to be observed at low magnifications, but they become visible in higher magnification BF TEM (Fig. 3a), and in HREM lattice images (Fig. 4). Digital selected area electron diffraction (Fig. 3b) shows a crystalline ring at the magnetite $2.96 \AA 220$ spacing (Fig. 3c), after subtraction of a matching pattern recorded under same conditions from area without phytoferritin. These preliminary results demonstrate that SAD and HREM structural data can be obtained from phytoferritin in unstained plant sections. [3]

[1] M. Gajdardziska-Josifovska, et al., European Journal of Mineralogy 13 (2001) 863.

[2] R.G. McClean, et al. European Journal of Mineralogy 13 (2001) 1235.

[3] Funded by NSF/DMR-9553148. We acknowledge T. P. Schuck for growing the plants. 

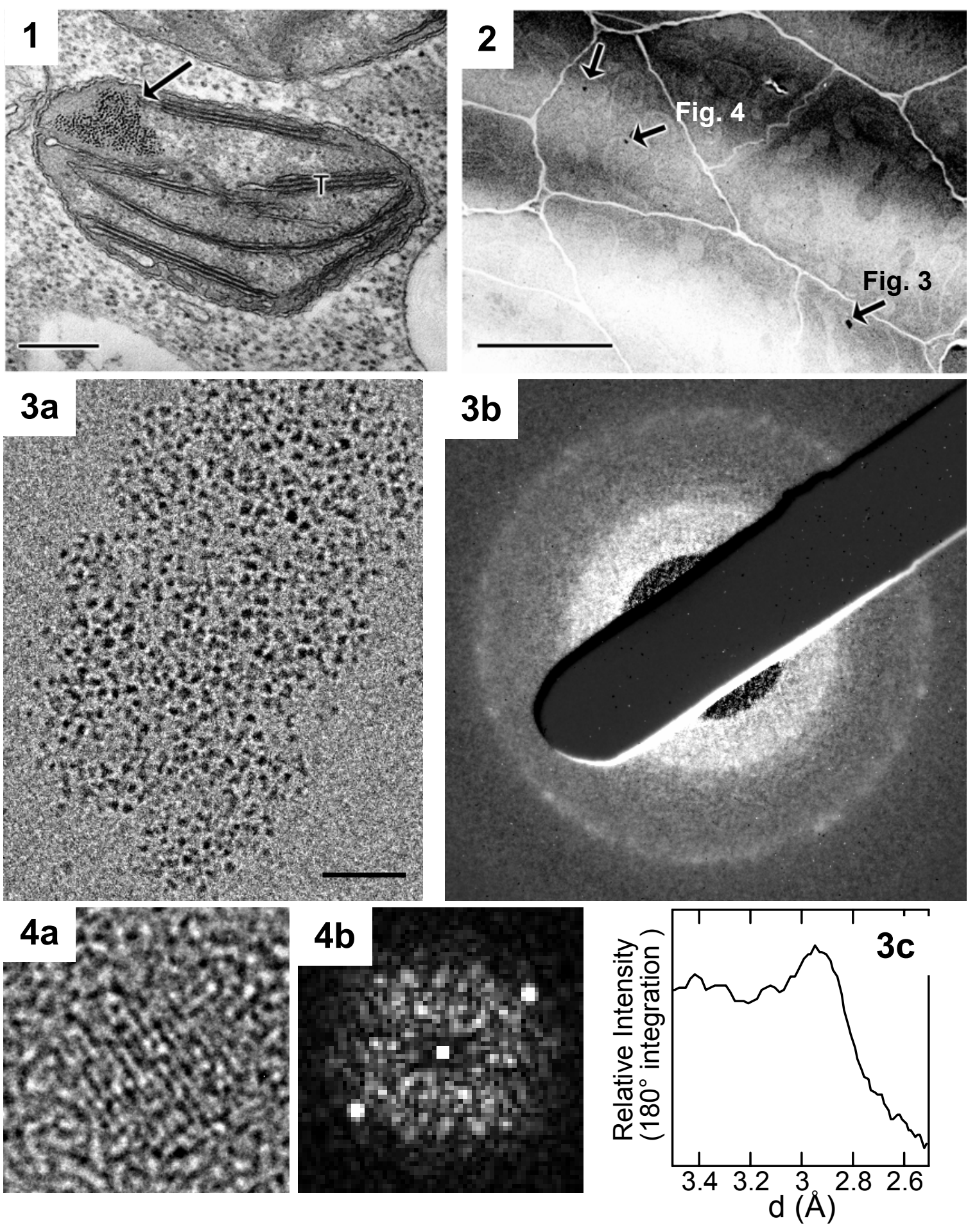

FIG. 1 Arrow indicates an agglomerate of phytoferritin particles located in the stroma outside of the thylakoid membrane (T) system within a chloroplast from an iron-treated bean leaf. Size bar $=0.25 \mu \mathrm{m}$. FIG. 2 Phytoferritin agglomerates are indicated by arrows in this micrograph of a section from an unosmicated, iron-treated bean leaf, imaged with $75 \mathrm{keV}$ electrons. Size bar $=5 \mu \mathrm{m}$.

FIG. 3 Phytoferritin agglomerate from Fig. 2 analyzed with $300 \mathrm{keV}$ electrons in unstained sample (a) BFTEM image, Size bar $=50 \mathrm{~nm}$; (b) Background subtracted SAD of agglomerate; (c) Profile of SAD.

Fig. 4 HREM of a single phytoferritin nanocrystal (a) and corresponding FFT for lattice spacing analysis (b). 